\title{
触 New Disease Reports \\ Association of Cotton leaf curl Multan virus and its associated betasatellite with leaf curl disease of Hibiscus rosa-sinensis in India
}

A. Srivastava, S. Kumar, M. Jaidi and S.K. Raj

Plant Molecular Virology Lab, CSIR-National Botanical Research Institute, Lucknow-226001, India

*E-mail: skraj2@rediffmail.com

Received: 25 Aug 2015. Published: 22 Jan 2016. Keywords: begomovirus

Hibiscus (Hibiscus rosa-sinensis) is a perennial ornamental plant grown for its attractive flowers. In September 2011, symptoms of severe leaf curling, vein thickening and enation were observed on $31 \%$ (13/42) hibiscus plants (Fig. 1) grown in a garden at Lucknow, India. The symptoms and whitefly infestation suggested a begomovirus infection.

Leaf samples from 13 diseased and four healthy hibiscus plants were collected. Total DNA was isolated and subjected to PCR using degenerate begomovirus primers

(CP-F: 5'-GCATCTGCAGGCCCACATYGTCTTYCCNGT-3' and CP-R 5'-AATACTGCAGGGCTTYCTRTACATRGG-3'). All samples of symptomatic leaves yielded a $\sim 1.2 \mathrm{~kb}$ PCR product indicative of a begomovirus. Full-length genomes were amplified by the rolling circle amplification method $(\sim 2.7 \mathrm{~kb})$ from two samples, and cloned and sequenced (GenBank Accession Nos. JN880418 and JN807763). Nucleotide sequence analysis revealed $99 \%$ identity between the two isolates, and $90-93 \%$ identity and close phylogenetic relationships with isolates of Cotton leaf curl Multan virus (CLCuMV) (Fig. 2). Hence, two new variants of CLCuMV were identified. Association with a betasatellite was tested by PCR with specific primers (Beta 01: $5^{\prime}$-AGCCTTAGCTACGCCGGAGC- $3^{\prime}$ and Beta 02: 5'-GCTGCGTAGCGTAGAGGTTT-3'). Again, all 13 samples of symptomatic leaves produced the expected product of $\sim 1.3 \mathrm{~kb}$. One amplicon was cloned and sequenced (KT447040). The sequence had 98\% nucleotide identity and close phylogenetic relationships with Cotton leaf curl Multan betasatellite (CLCuMB) isolates (Fig. 3), and was concluded to be an isolate of CLCuMB. The disease incidence was confirmed during a survey of the same garden in September 2015. Twenty three of the 42 hibiscus plants investigated by dot blot analysis using a CLCuMV-specific probe (derived from clone JN880418) were found to be infected (Fig. 4).

The natural occurrence of CLCuMV and CLCuMB has been reported on hibiscus from China (Mao et al., 2008), whereas Cotton leaf curl Burewala virus with CLCuMB on hibiscus has been reported from Pakistan (Akhtar et al., 2014). However, this is the first report of CLCuMV and CLCuMB on hibiscus from India.

\section{References}

Akhtar KP, Ullah R, Saeed M, Sarwar N, Mansoor S, 2014. China rose (Hibiscus rosa-sinensis): a new natural host of Cotton leaf curl Burewala virus in Pakistan. Journal of Plant Pathology 96, 385-389. http://dx.doi.org/10.4454/JPP.V96I1.045

Mao MJ, He ZF, Yu H, Li HP, 2008. Molecular characterization of cotton leaf curl Multan virus and its satellite DNA that infects Hibiscus rosasinensis. Chinese Journal of Virology 24, 64-68.

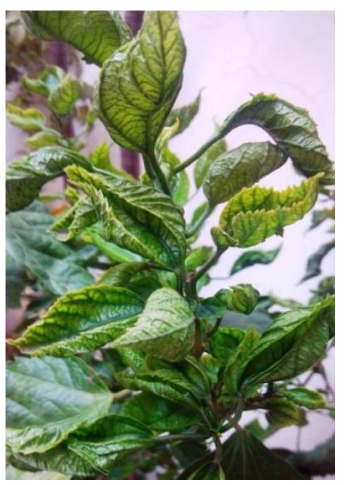

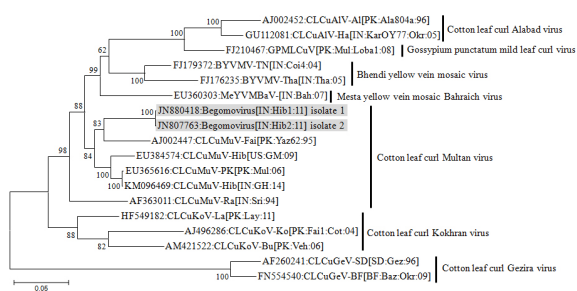

Figure 2

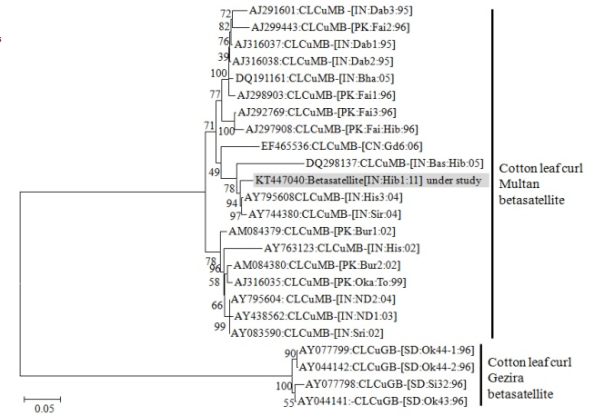

Figure 3

Figure 1
\begin{tabular}{|ccccccccc|}
\hline 1 & 2 & 3 & 4 & 5 & 6 & 7 & 8 \\
& 0 & 0 & 0 & 0 & 0 & & 0 \\
9 & 10 & 11 & 12 & 13 & 14 & 15 & 16 \\
0 & 0 & 0 & 0 & 0 & 0 & 0 & 0 \\
17 & 18 & 19 & 20 & .21 & 22 & 23 & PC \\
0 & 0 & 0 & & 0 & 0 & 0 & 0
\end{tabular}

Figure 4

To cite this report: Srivastava A, Kumar S, Jaidi M, Raj SK, 2016. Association of Cotton leaf curl Multan virus and its associated betasatellite with leaf curl disease of Hibiscus rosa-sinensis in India. New Disease Reports 33, 4. http://dx.doi.org/10.5197/j.2044-0588.2016.033.004 